\title{
Impact of low-carbohydrate diet on renal function: a meta-analysis of over 1000 individuals from nine randomised controlled trials
}

\author{
Chikako Oyabu, Yoshitaka Hashimoto, Takuya Fukuda, Muhei Tanaka, Mai Asano, Masahiro Yamazaki \\ and Michiaki Fukui* \\ Department of Endocrinology and Metabolism, Graduate School of Medical Science, Kyoto Prefectural University of Medicine, \\ Kyoto 602-8566, Japan
}

(Submitted 22 January 2016 - Final revision received 29 March 2016 - Accepted 29 April 2016 - First published online 27 June 2016)

\section{Abstract}

We aimed to clarify the effect of low-carbohydrate diet (LCD) on renal function in overweight and obese individuals without chronic kidney disease (CKD). Literature searches were performed using EMBASE, MEDLINE and Cochrane Library until December 2015. We selected articles that reported human studies from their inception until December 2015 in English using the following searching terms: 'Low carbohydrate diet' AND ('Clinical trial' OR 'Clinical study' OR 'Clinical investigation' OR 'Observational study' OR 'Cohort study'). We compared the effects of LCD on renal function, defined as change in estimated glomerular filtration rate (eGFR), assessed in randomisedcontrolled trials. We calculated the mean change in eGFR and the mean change in standard deviations by eGFR or creatinine clearance, and compared the mean change in eGFR and standard deviations in LCD with those in the control diet using fixed-effects models. We selected nine randomised controlled trials including 1687 participants ( 861 were fed LCD and 826 were fed the control diet). The mean change in eGFR in the LCD group was -4.7 to $24.0 \mathrm{ml} / \mathrm{min}$ per $1.73 \mathrm{~m}^{2}$ and that in the control diet group was -4.1 to $10.8 \mathrm{ml} / \mathrm{min}^{\mathrm{per}} 1.73 \mathrm{~m}{ }^{2}$. The mean change in eGFR in the LCD group was greater than that in the control diet $\left(0.13 \mathrm{ml} / \mathrm{min}\right.$ per $1.73 \mathrm{~m}^{2} ; 95 \%$ CI $\left.0 \cdot 00,0 \cdot 26\right)$. In the present meta-analysis, we identified that the increase in eGFR was greater in LCD compared with the control diet in overweight and obese individuals without CKD.

\section{Key words: Low-carbohydrate diets: Renal function: Obesity: Meta-analyses}

Obesity, which is a major public health problem worldwide ${ }^{(1)}$, is an important factor for the development and progression of several lifestyle-associated diseases such as hypertension ${ }^{(2)}$, type 2 diabetes ${ }^{(3,4)}$ and $\mathrm{CVD}^{(5)}$. In addition, it has been shown that obesity is associated with the prevalence and progression of chronic kidney disease (CKD) ${ }^{(6-8)}$.

Dietary treatments are effective for weight loss ${ }^{(9)}$; however, there is currently no consensus on the optimal dietary therapy for weight loss and the prevention of further events. Recently, low-carbohydrate diet (LCD) has been recognised as a weight-loss strategy. Several studies have investigated the effectiveness of LCD for weight loss ${ }^{(10-12)}$. Furthermore, a highprotein diet corresponding with LCD promotes weight loss, maintains lean body mass and improves lipid and glycaemic metabolism in obese individuals ${ }^{(13,14)}$.

Meanwhile, there is concern about the safety of LCD and corresponding high protein intake on renal function. Previous studies have revealed that high-protein diets are associated with the development and progression of CKD in obese individuals $^{(15)}$. In addition, it has been reported that individuals who reduced protein intake inhibit renal death, compared with those with higher or unrestricted protein intakes ${ }^{(16)}$. Furthermore, it has been reported that dietary protein restriction slows the progression of renal dysfunction among individuals with $\mathrm{CKD}^{(17)}$, and that a protein limit of $0.8 \mathrm{~g} / \mathrm{kg}$ for patients with renal dysfunction has been recommended in the KDOQI guidelines $^{(18)}$. Thus, there is a possibility that LCD has adverse effects on renal function; however, it remains to be elucidated the impact of LCD on renal function in obese individuals. Therefore, we aimed to investigate the effect of LCD on renal function, defined as estimated glomerular filtration rate (eGFR) or creatinine clearance (CCR), among overweight and obese individuals without CKD in this meta-analysis.

\section{Methods \\ Data sources and searches}

Literature search was performed using EMBASE, MEDLINE and Cochrane Library. We selected articles that reported human studies from their inception until December 2015 in English using the following searching terms: 'Low carbohydrate diet' AND

Abbreviations: CKD, chronic kidney disease; eGFR, estimated glomerular filtration rate; LCD, low-carbohydrate diet.

* Corresponding author: M. Fukui, fax +81 75252 3721, email sayarinapm@hotmail.com 
('Clinical trial' OR 'Clinical study' OR 'Clinical investigation' OR 'Observational study' OR 'Cohort study').

\section{Study selection}

Inclusion criteria were as follows: (1) the articles should be original, (2) the abstracts of articles should include the term or abbreviations of 'low carbohydrate diet', (3) the study should include overweight, $25 \leq \mathrm{BMI}<29.9 \mathrm{~kg} / \mathrm{m}^{2}\left(23 \leq \mathrm{BMI}<24.9 \mathrm{~kg} / \mathrm{m}^{2}\right.$ if Asian), and obese, BMI $\geq 30 \mathrm{~kg} / \mathrm{m}^{2}$ (BMI $\geq 25 \mathrm{~kg} / \mathrm{m}^{2}$ if Asian) individuals $^{(19)}$ and (4) duration $\geq 6$ months. Exclusion criteria included (1) duplicated article in three websites, (2) no original raw data for creatinine, eGFR or CCR, (3) no data on standard deviation for assessed data or (4) no data on the control group. For this meta-analysis, trials were required to use a randomisedcontrolled design comparing the effects of LCD diet, defined as allowing a maximum intake of $45 \%$ of energy from carbohydrates, with control diet ${ }^{(20)}$.

\section{Data extraction}

We extracted the following data from all assessed articles: authors, study title, country, year of publication, study design, study length, sex distribution, age, sample size, dropout rate, intervention for diets and outcomes.

In this meta-analysis, we considered CCR as eGFR ${ }^{(21)}$. In the study by Krebs et $a l^{(22)}$ and Stern et $a l .{ }^{(23)}$, not eGFR but serum creatinine at the end point was described. Thus, we calculated eGFR from the following equation: $\mathrm{eGFR}=175 \times \mathrm{age}^{-0 \cdot 203} \times$ serum creatinine ${ }^{-1 \cdot 154}(\times 0.742 \text { if female })^{(24)}$. The mean change in eGFR during the courses of the studies was set as the primary outcome of interest in this meta-analysis.

In some studies, we found only the average and standard deviations of eGFR at baseline and at the end point. In these cases, we estimated the mean change in eGFR as follows: eGFR at the end point - eGFR at baseline. In the same way, we calculated SD of change in eGFR as follows: SD of change in $\mathrm{eGFR}=$ the square root of (the square (sD of eGFR at the end point) + the square (eGFR at baseline))

\section{Validity and quality assessment}

For the analysis, two reviewers independently checked and selected all references, respectively. We assessed quality of evidence for each study by using the Grading of Evidence, Assessment, Development and Evaluation approach ${ }^{(25)}$. We validated and performed quality assessment of our systematic review using the Assessment of Multiple Systematic Reviews tool $^{(26)}$.

\section{Quantitative data synthesis}

We performed quantitative data synthesis based on Preferred Reporting Items for Systematic Reviews and Meta-Analyses (PRISMA) statement ${ }^{(27)}$. We analysed the impact of LCD on renal function compared with that of the control diet among overweight and obese participants without CKD, defined as eGFR $<60 \mathrm{ml} / \mathrm{min}$ per $1.73 \mathrm{~m}^{2}$ at baseline ${ }^{(28)}$. As the study by Tirosh et al. ${ }^{(29)}$ included ninety-nine participants with CKD, we excluded them from the analysis.

We performed a meta-analysis to provide quantitative summary estimates of mean change in eGFR of LCD compared with the control diet. Summary averages were calculated using fixed-effects model according to Mantel \& $\mathrm{Haenszel}^{(30)}$. Statistical significance was defined at $P$ values $<0 \cdot 05$. The $I^{2}$ statistic was calculated to assess statistical heterogeneity across studies: $0 \%$ suggests no heterogeneity, 0-25\% very low heterogeneity, 25-50\% low heterogeneity, 50-75\% moderate heterogeneity and a value of $75 \%$ high heterogeneity ${ }^{(31)}$.

A funnel plot was produced for intervention effects to compare each study. Asymmetry may indicate reporting bias, heterogeneity or may occur by chance. All analyses were conducted using R version 3.0.1 (R project for Statistical Computing).

\section{Result}

We collected 205 articles from EMBASE, MEDLINE and Cochrane Library. Among them, 194 articles did not report original data. Renal function was assessed in eleven articles ${ }^{(24,29,32-39)}$;

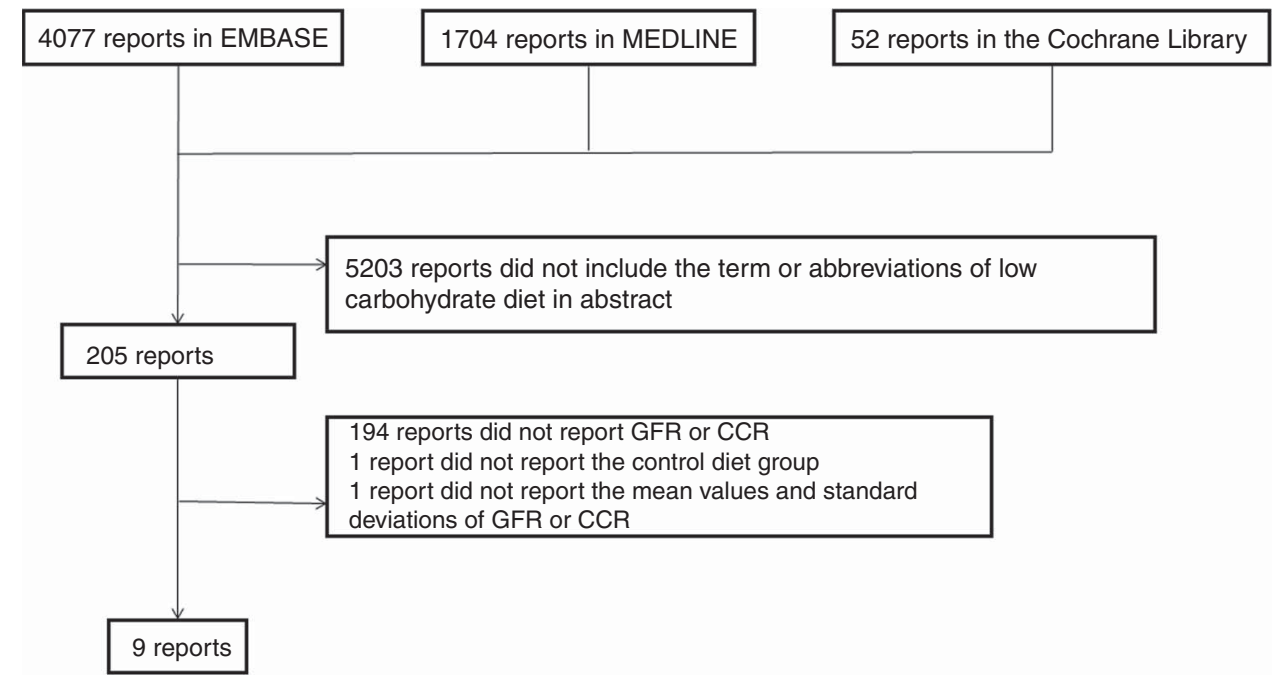

Fig. 1. Flow diagram of study selection. GFR, glomerular filtration rate; CCR, creatinine clearance. 
however, one of them was excluded because the control group was not assessed ${ }^{(38)}$, and another was excluded because it did not report data on mean values and standard deviations ${ }^{(39)}$. Finally, we evaluated nine randomised controlled trials (Fig. 1).

Characteristics of the nine randomised controlled trials are presented in Table 1. These studies included 1687 participants, 861 were in the LCD group and 826 in the control group; $46.2 \%$ of them (779 of 1687) were male. The study duration ranged from 6 to 24 months. Among nine studies, four were conducted on patients with diabetes.

Proportion of carbohydrate intake in the LCD group in these studies was significantly lower than that of the control group. On the other hand, the definition of LCD was not identical among selected studies, with carbohydrate consumption ranging from 4 to $45 \%$ of total energy intake. Total energy and dietary macronutrient composition were not maintained during the follow-up period (Table 2). Even in the LCD group, we found an increasing trend in carbohydrate intakes during the follow-up periods. In addition, the dropout rate was high in most studies ${ }^{(22,12,32-36)}$.

We did not find asymmetry in the funnel plot (Fig. 2); thus, the risk of publication bias in this meta-analysis was thought to be low. On the basis of the quality assessment, the quality of each study was at medium level, although all studies were not of high level.

To compare the effect of LCD on renal function, the participants who dropped out were excluded from the analysis. Therefore, the meta-analysis encompassed a total of 972 participants, with 452 in the LCD group and 520 in the control group. All studies were combined with the fixed-effects model, and the mean change in eGFR in the LCD group was evaluated in comparison with that in the control group. The mean change in eGFR in the LCD group was -4.7 to $24.0 \mathrm{ml} / \mathrm{min}$ per $1.73 \mathrm{~m}^{2}$ and that in the control group was -4.1 to $10.8 \mathrm{ml} / \mathrm{min}$ per $1.73 \mathrm{~m}^{2}$. The mean change in eGFR in the LCD group was greater than that in the control group $\left(0.13 \mathrm{ml} / \mathrm{min}\right.$ per $1.73 \mathrm{~m}^{2}$; 95\% CI 0.00, 0.26) (Fig. 3).

\section{Discussion}

In this present meta-analysis of randomised controlled trials comparing LCD with control diets, we identified that the increase in eGFR in LCD was greater than that in the control group among overweight and obese individuals without CKD.

Obesity is associated with the prevalence and progression of $\mathrm{CKD}^{(6-8)}$, and lifestyle interventions including dietary treatment improve body weight in obese individuals ${ }^{(40)}$. LCD and corresponding high-protein diets have been recognised as the effective treatment to control body weight ${ }^{(10-12)}$. In addition, it has been reported that LCD improved CVD risk factors at short term ${ }^{(41)}$. In contrast, it has been reported that LCD is a potential risk for renal dysfunction, because LCD is associated with high protein intake. A recent study showed that LCD does not negatively affect eGFR compared with a low-fat diet among obese individuals ${ }^{(36)}$. We ensured that LCD did not negatively affect eGFR in overweight and obese individuals without CKD in this meta-analysis.

The possible reasons why LCD is effective for renal function are as follows. Obesity is related to the prevalence and the

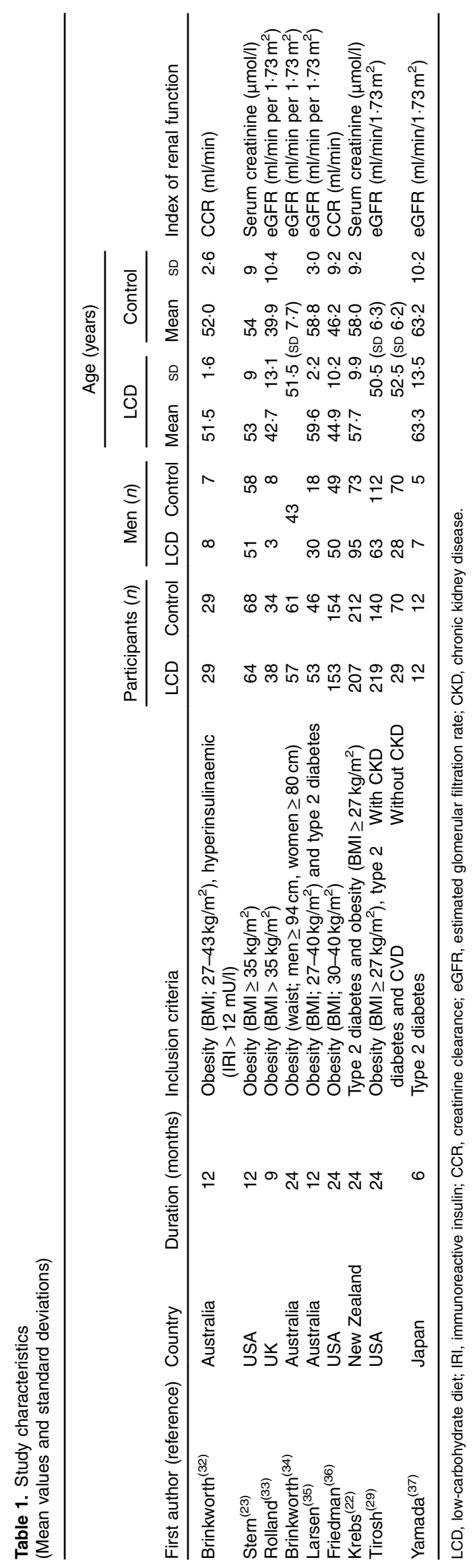


Table 2. Dietary target and nutrition intake

(Mean values and standard deviations)

\begin{tabular}{|c|c|c|c|c|c|c|}
\hline \multirow[b]{2}{*}{ First author (reference) } & \multicolumn{2}{|c|}{ Intervention dietary target } & \multicolumn{2}{|c|}{ Nutrition intake at end point } & \multicolumn{2}{|c|}{ Dropout rate $(\%)$} \\
\hline & LCD & Control & LCD & Control & LCD & Control \\
\hline Brinkworth ${ }^{(32)}$ & $\begin{array}{l}\text { C: } 40 \%,<140 \mathrm{~g} / \mathrm{d} \\
\text { P: } 30 \%,<110 \mathrm{~g} / \mathrm{d} \\
\text { F: } 30 \%,<50 \mathrm{~g} / \mathrm{d}\end{array}$ & $\begin{array}{l}\text { C: } 55 \%,<200 \mathrm{~g} / \mathrm{d} \\
\text { P: } 15 \%,<60 \mathrm{~g} / \mathrm{d} \\
\text { F: } 30 \%,<50 \mathrm{~g} / \mathrm{d}\end{array}$ & $\begin{array}{l}\mathrm{E}: 7600(\mathrm{sD} 600) \mathrm{kJ} \\
\mathrm{C}: 46.4(\mathrm{SD} 1.6) \% \\
\mathrm{P}: 21.5(\mathrm{SD} 0.8) \% \\
\mathrm{~F}: 31.0(\mathrm{SD} 1.2) \%\end{array}$ & $\begin{array}{l}\mathrm{E}: 9000(\text { (SD } 800) \mathrm{kJ} \\
\mathrm{C}: 46 \cdot 3(\mathrm{SD} 1.3) \% \\
\mathrm{P}: 20.5(\mathrm{SD} 0.7) \% \\
\mathrm{~F}: 32 \cdot 4(\mathrm{SD} 1.1) \%\end{array}$ & 28 & 25 \\
\hline Stern ${ }^{(23)}$ & $\begin{array}{l}\text { C: reduce }<30 \mathrm{~g} / \mathrm{d} \\
\text { P, F: no restriction }\end{array}$ & E: reduce $2092 \mathrm{~kJ} / \mathrm{d}$ with $<30 \%$ from $\mathrm{F}$ & $\begin{array}{l}\text { E: } 1462(\text { (SD 776) kJ } \\
\text { C: } 120(\text { SD 93) g } \\
\text { P: } 73(\text { SD 34) g } \\
\text { F: } 93(\text { SD 117) g }\end{array}$ & $\begin{array}{l}\text { E: } 1822(\text { SD 1008) kJ } \\
\text { C: } 230(\text { SD 150) } \mathrm{g} \\
\text { P: } 74(\text { SD 50) g } \\
\text { F: } 69(\text { SD 48)g }\end{array}$ & 31 & 37 \\
\hline Rolland $^{(33)}$ & $\begin{array}{l}\text { E: } 3347-6276 \mathrm{~kJ} \\
\text { C: }<40 \mathrm{~g} \\
\text { (3347 kJ: C: } 20 \%, \text { P: } 40 \%, \text { F: } 40 \%)\end{array}$ & $\begin{array}{l}\text { E: } 2301 \mathrm{~kJ} \\
\text { C: } 36 \% \\
\text { P: } 36 \% \\
\text { F: } 28 \%\end{array}$ & - & - & 48 & 59 \\
\hline Brinkworth ${ }^{(34)}$ & $\begin{array}{l}\text { C: } 4 \%, 14 \mathrm{~g} / \mathrm{d} \\
\text { P: } 35 \%, 124 \mathrm{~g} / \mathrm{d} \\
\text { F: } 61 \%, 99 \mathrm{~g} / \mathrm{d}\end{array}$ & $\begin{array}{l}\text { C: } 46 \%, 162 \mathrm{~g} / \mathrm{d} \\
\text { P: } 24 \%, 85 \mathrm{~g} / \mathrm{d} \\
\text { F: } 39 \%, 49 \mathrm{~g} / \mathrm{d}\end{array}$ & - & - & 43 & 37 \\
\hline Larsen $^{(35)}$ & $\begin{array}{l}\text { E: }<6400 \mathrm{~kJ} \text { or } 30 \% \\
\text { Restriction } \\
\text { C: } 40 \% \\
\text { P: } 30 \% \\
\text { F: } 30 \%\end{array}$ & $\begin{array}{l}\text { E: }<6400 \mathrm{~kJ} \text { or } 30 \% \\
\text { Restriction } \\
\text { C: } 55 \% \\
\text { P: } 15 \% \\
\text { F: } 30 \%\end{array}$ & $\begin{array}{l}\text { E: } 6664 \mathrm{~kJ} \\
\text { C: } 41 \cdot 8 \% \\
\text { P: } 26 \cdot 5 \% \\
F: 30 \cdot 7 \%\end{array}$ & $\begin{array}{l}\text { E: } 6628 \mathrm{~kJ} \\
\text { C: } 48 \cdot 2 \% \\
\text { P: } 18.9 \% \\
F: 32.0 \%\end{array}$ & 19 & 20 \\
\hline Friedman $^{(36)}$ & $\begin{array}{l}\text { Atkins' diet } \\
\text { C: } 20 \mathrm{~g} / \mathrm{d} \times 2 \text { weeks and then increase } 5 \mathrm{~g} / \mathrm{d} \\
\text { P, F: no restriction }\end{array}$ & $\begin{array}{l}\text { Men: } 6276-7531 \mathrm{~kJ} \\
\text { Women: } 5021-6276 \mathrm{~kJ} \\
\text { C: } 55 \% \\
\text { P: } 15 \% \\
\text { F: } 30 \%\end{array}$ & - & - & 64 & 58 \\
\hline Krebs $^{(22)}$ & $\begin{array}{l}\text { C: } 40 \% \\
\text { P: } 30 \% \\
\text { F: } 30 \%\end{array}$ & $\begin{array}{l}\text { C: } 55 \% \\
\text { P: } 15 \% \\
\text { F: } 30 \%\end{array}$ & $\begin{array}{l}\text { E: } 7170(\text { (sD } 1973 \cdot 6) \mathrm{kJ} \\
\text { C: } 45 \cdot 5(\text { SD } 6 \cdot 9) \% \\
\text { P: } 20.6(\text { SD } 3.9) \% \\
\text { F: } 32 \cdot 8(\text { SD } 6.3) \%\end{array}$ & 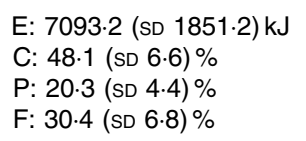 & 31 & 30 \\
\hline Tirosh ${ }^{(29)}$ & $\begin{array}{l}\mathrm{C}: 20 \mathrm{~g} / \mathrm{d} \times 2 \text { months } \\
\text { non-restricted energy content } \\
\mathrm{P}, \mathrm{F}: \text { no restriction }\end{array}$ & $\begin{array}{l}\text { 1, Low-fat diet }(\mathrm{F}:<30 \%) \\
2 \text {, Mediterranean diet } \\
6276-7531 \mathrm{~kJ} / \mathrm{d}(1500-1800 \mathrm{kcal} / \mathrm{d}) \\
\quad(\mathrm{F}:<35 \%)\end{array}$ & - & - & & \\
\hline Yamada $^{(37)}$ & $\begin{array}{l}\text { C: } 70-130 \mathrm{~g} / \mathrm{d} \\
\text { P, F: no restriction }\end{array}$ & $\begin{array}{l}\text { E: HT }\left(\mathrm{m}^{2}\right) \times 22 \times 25 \times 4.18605 \mathrm{~kJ} \\
\text { C: } 50-60 \% \\
\text { P: } 1 \cdot 0-1 \cdot 2 \mathrm{~g} / \mathrm{kg} \\
\text { F: }<25 \%\end{array}$ & $\begin{array}{l}\text { E: } 6837 \text { (SD 2222) kJ } \\
\text { C: } 29.8 \text { (SD 12.5) \% } \\
\text { P: } 25.3(\text { (SD } 7.3) \% \\
\text { F: } 45.4 \text { (SD } 8.9) \%\end{array}$ & $\begin{array}{l}\text { E: } 6736(\text { SD } 1619) \mathrm{kJ} \\
\text { C: } 51.0(\text { SD } 4.6) \% \\
\text { P: } 16.6(\text { SD } 2.8) \% \\
\text { F: } 32.3(\text { SD } 5.2) \%\end{array}$ & 0 & 0 \\
\hline
\end{tabular}

LCD, low-carbohydrate diet; C, carbohydrate; P, protein; F, fat; E, energy; HT, height. 
progression of $\mathrm{CKD}^{(6-8)}$; therefore, weight loss by LCD might lead to improvement in renal function. In fact, some studies have revealed that $\mathrm{LCD}$ was effective for weight loss ${ }^{(42,43)}$. In this meta-analysis, body weight decreased significantly from baseline in both LCD and control diet groups; however, there was no significant difference between the LCD and control diet groups with regard to change in body weight (data not shown). On the other hand, there is also a possibility that the increase in eGFR did not reflect improvement of renal function. As creatinine generation is determined by muscle mass and creatinine consumption, LCD and corresponding high-protein diets lead to glomerular hyperfiltration, glomerular hypertrophy and increased glomerular pressure, which might be both a cause and a consequence of renal injury ${ }^{(44)}$. Glomerular hyperfiltration could be caused by afferent arteriolar vasodilation as seen in patients with diabetes or after a high-protein diet, and/or by efferent arteriolar vasoconstriction owing to activation of the renin-angiotensin-aldosterone system $^{(44)}$. According to a systematic review of glomerular hyperfiltration assessment, however, the definition of glomerular hyperfiltration threshold ranged from 90.7 to $175 \mathrm{ml} / \mathrm{min}$ per

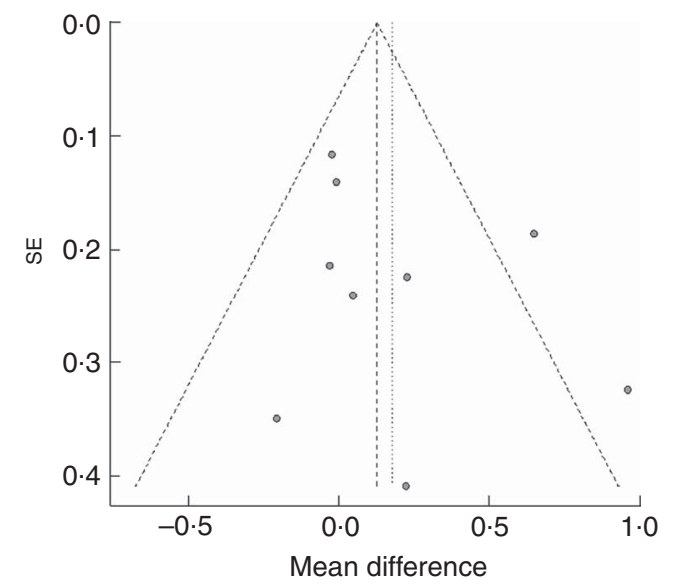

Fig. 2. Funnel plot of nine randomised controlled trials in overweight and obese individuals without chronic kidney disease.
$1.73 \mathrm{~m}^{2(45)}$. In this meta-analysis, the mean eGFR values at the end point were $69.4-124.2 \mathrm{ml} / \mathrm{min}$ per $1.73 \mathrm{~m}^{2}$ in the LCD group and $65.0-112.6 \mathrm{ml} / \mathrm{min}$ per $1.73 \mathrm{~m}^{2}$ in the control group.

In this study, although the mean change in eGFR in the LCD group was greater than that in the control group, the difference was very low. Therefore, the clinical significance of LCD on renal function might not be great. However, this meta-analysis showed that LCD and the corresponding high-protein diet was not harmful for renal function in overweight and obese individuals without renal dysfunction.

A previous study showed that the adverse effect of highprotein diets on renal function occurred only after long-term follow-up, such as 3 or more years ${ }^{(46)}$. There is a possibility that the adverse effect of LCD on renal function might not have appeared yet. Thus, we cannot deny the possibility that observational periods might not be enough, and further longterm studies are needed.

The present study has several limitations. First, the definition of LCD was inconsistent and extreme carbohydrate restrictions such as under $40 \mathrm{~g} / \mathrm{d}$ and $4 \%$ of total energy content ${ }^{(33,34)}$ were included among these studies. Second, the dropout rate was relatively high in most studies ${ }^{(22,23,32-36)}$. In this meta-analysis, the dropout rate of six studies ${ }^{(22,23,32-34,36)}$ were over $20 \%$. In addition, poor adherence of study participants is also a limitation. Most of the participants in this study were not able to achieve and maintain target diet macronutrient compositions. In fact, the macronutrient composition tended to be restored to baseline proportions in these study participants, indicating that it is difficult to change the habitual dietary patterns to another dietary pattern. The motivation of participants was also important and this affected retention rates. In fact, several studies revealed that adherence to the diet was greatly diminished after the first few months ${ }^{(47)}$. Participants who completed the study may have represented a group of motivated participants, and this could have potentially biased the observed effects and might limit the generalisability of the findings. Thus, not randomised controlled trials but observational studies might be suitable for evaluating the effect of diet treatment ${ }^{(10)}$. Third, the sample size was relatively small and the study duration was

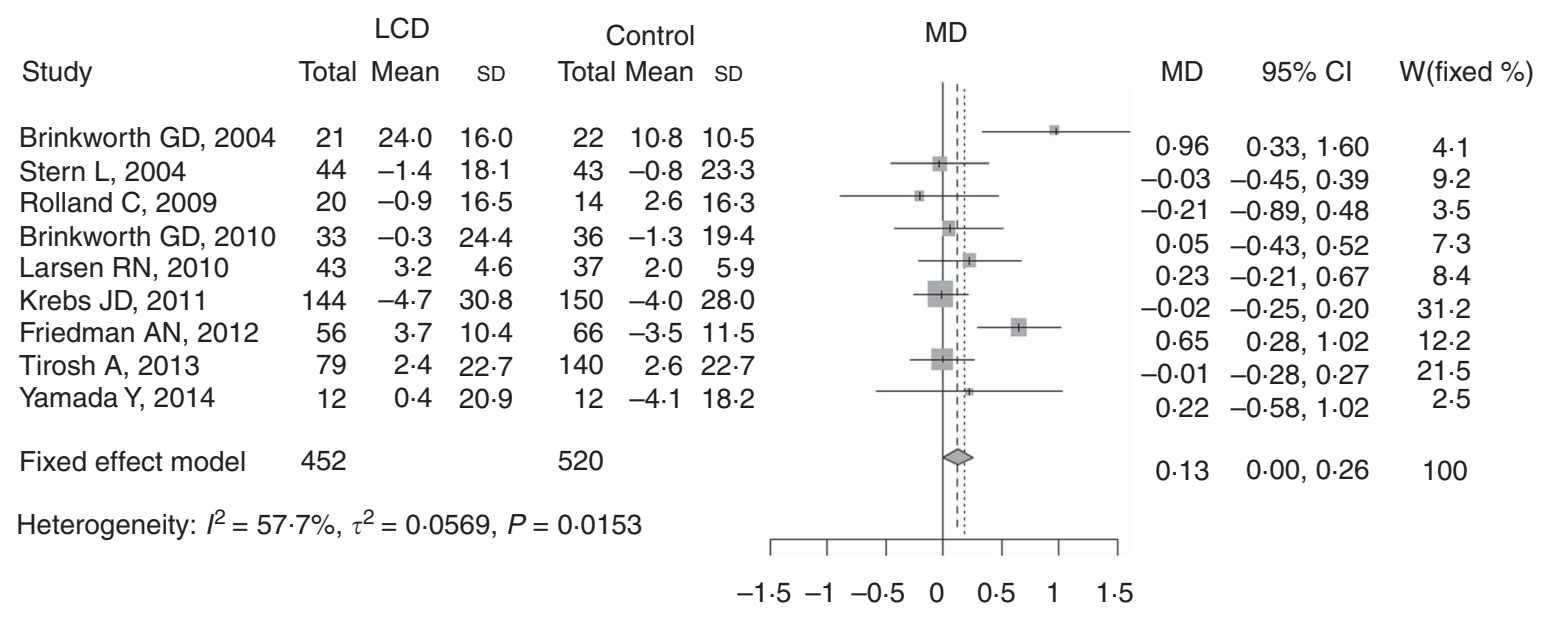

Fig. 3. Forest plot for change in estimated glomerular filtration rate associated with low-carbohydrate diet (LCD) among individuals without chronic kidney disease. The size of the boxes corresponds to each study's weight. MD, mean difference, W, weight. 
short to provide clear effects of LCD on renal function. Further studies with larger sample sizes and long-term duration are required in order to elucidate the long-term safety and efficacy of this dietary strategy on renal function. Fourth, eGFR was not directly measured, although our findings are consistent with previously reported effects on $\mathrm{eGFR}^{(46)}$. Fifth, there is a possibility that participants who develop renal issues would not continue with the trial and would likely withdraw, and it is possible that such an effect could have been missed in this meta-analysis. Sixth, the changes in proteinuria, microalbuminuria and macroalbuminuria could be more important than that of eGFR. We have also searched for changes in proteinuria, microalbuminuria and macroalbuminuria; six studies $^{(22,35-37,39,48)}$ have reported data on microalbuminuria. However, four studies ${ }^{(22,35,36,39)}$ did not show data on mean values and standard deviations. Therefore, we could not perform a meta-analysis. Further studies are needed to determine the effects of LCD on proteinuria, microalbuminuria and macroalbuminuria. Finally, we did not provide any assessment of physical activity or other lifestyle habits except the diet therapy.

In conclusion, this meta-analysis revealed that the increase in eGFR in the LCD group was greater than that in the control group in overweight and obese individuals without CKD in at least 6 to 24 months.

\section{Acknowledgements}

M. A., M. Y. and M. F. have received grants, honoraria and research supports from AstraZeneca plc., Astellas Pharma Inc., Nippon Boehringer Ingelheim Co., Ltd, Daiichi Sankyo Co., Ltd, Eli Lilly Japan K.K., Kyowa Hakko Kirin Company Ltd, Kissei Pharmaceutical Co., Ltd, MSD K.K, Mitsubishi Tanabe Pharma Corporation, Novo Nordisk Pharma Ltd. Sanwa Kagaku Kenkyusho Co., Ltd, Sanofi K.K., Ono Pharmaceutical Co., Ltd and Takeda Pharmaceutical Co., Ltd. The sponsors were not involved in the study design; in the collection, analysis, interpretation of data; in the writing of this manuscript; or in the decision to submit the article for publication.

C. O., Y. H., T. F., M. T., M. A., M. Y. and M. F. analysed the data; C. O. and Y. H. reviewed the articles; C. O. wrote the manuscript; Y. H., T. F., M. T., M. A. and M. Y. contributed to the discussion; and M. F.: reviewed/edited the manuscript.

M. A., M. Y. and M. F., their immediate families and any research foundations with which they are affiliated have not received any financial payments or other benefits from any commercial entity related to the subject of this article. The authors declare that, although they are affiliated with a department that is supported financially by a pharmaceutical company, the authors received no current funding for this study and this does not alter their adherence to all the journal policies on sharing data and materials. C. O., Y. H., T. F. and M. T. have nothing to disclose.

\section{References}

1. Kelly T, Yang W, Chen CS, et al. (2008) Global burden of obesity in 2005 and projections to 2030. Int J Obes (Lond) $\mathbf{3 2}$, 1431-1437.
2. Gelber RP, Gaziano JM, Manson JE, et al. (2007) A prospective study of body mass index and the risk of developing hypertension in men. Am J Hypertens 20, 370-377.

3. Chan JM, Rimm EB, Colditz GA, et al. (1994) Obesity, fat distribution, and weight gain as risk factors for clinical diabetes in men. Diabetes Care 17, 961-969.

4. Colditz GA, Willett WC, Rotnitzky A, et al. (1995) Weight gain as a risk factor for clinical diabetes mellitus in women. Ann Intern Med 122, 481-486.

5. Hubert HB, Feinleib M, McNamara PM, et al. (1983) Obesity as an independent risk factor for cardiovascular disease: a 26-year follow-up of participants in the Framingham Heart Study. Circulation 67, 968-977.

6. Kramer H, Luke A, Bidani A, et al. (2005) Obesity and prevalent and incident CKD: the hypertension detection and follow-up program. Am J Kidney Dis 46, 587-594.

7. Gelber RP, Kurth T, Kausz AT, et al. (2005) Association between body mass index and CKD in apparently healthy men. Am J Kidney Dis 46, 871-880.

8. Iseki K, Ikemiya Y, Kinjo K, et al. (2004) Body mass index and the risk of development of end-stage renal disease in a screened cohort. Kidney Int 65, 1870-1876.

9. Knowler WC, Barrett-Connor E \& Fowler SE (2002) Reduction in the incidence of type 2 diabetes with lifestyle intervention or metformin. $N$ Engl J Med 346, 393-403.

10. Hession M, Rolland C, Kulkarni U, et al. (2009) Systematic review of randomized controlled trials of low-carbohydrate vs. low-fat/low-calorie diets in the management of obesity and its comorbidities. Obes Rev 10, 36-50.

11. Bravata DM, Sanders L, Huang J, et al. (2007) Efficacy and safety of low-carbohydrate diets: a systematic review. JAMA 289, 1837-1850.

12. Samaha FF, Iqbal $\mathrm{N}$, Seshadri $\mathrm{P}$, et al. (2003) A low-carbohydrate as compared with a low-fat diet in severe obesity. N Engl J Med 348, 2074-2081.

13. Layman DK, Evans E, Baum JI, et al. (2005) Dietary protein and exercise have additive effects on body composition during weight loss in adult women. J Nutr $\mathbf{1 3 5}$, 1903-1910.

14. Due A, Toubro S, Skov AR, et al. (2004) Effect of normal-fat diets, either medium or high in protein, on body weight in overweight subjects: a randomised 1-year trial. Int J Obes Relat Metab Disord 28, 1283-1290.

15. Friedman AN (2004) High-protein diets: potential effects on the kidney in renal health and disease. Am J Kidney Dis 44, 950-962.

16. Mandayam S \& Mitch WE (2006) Dietary protein restriction benefits patients with chronic kidney disease. Nephrology (Carlton) 11, 53-57.

17. Modification of Diet in Renal Disease Study Group (1996) Effects of dietary protein restriction on the progression of moderate renal disease in the Modification of Diet in Renal Disease Study. J Am Soc Nephrol 7, 2616-2626.

18. Kidney Disease Outcomes Quality Initiative (2007) KDOQI Clinical Practice Guidelines and Clinical Practice Recommendations for Diabetes and Chronic Kidney Disease. Am J Kidney Dis 49, S12-S154.

19. World Health Organization (2000) The Asia-Pacific Perspective: Redefining Obesity and its Treatment. Melbourne: International Diabetes Institute, Health Communications Australia Pty. Ltd.

20. Hu T, Mills KT, Yao L, et al. (2012) Effects of low-carbohydrate diets versus low-fat diets on metabolic risk factors: a meta-analysis of randomized controlled clinical trials. Am J Epidemiol 176, S44-S54. 
21. Pan Y, Guo LL \& Jin HM (2008) Low-protein diet for diabetic nephropathy: a meta-analysis of randomized controlled trials. Am J Clin Nutr 88, 660-666.

22. Krebs JD, Elley CR, Parry-Strong A, et al. (2012) The Diabetes Excess Weight Loss (DEWL) Trial: a randomised controlled trial of high-protein versus high-carbohydrate diets over 2 years in type 2 diabetes. Diabetologia 55, 905-914.

23. Stern L, Iqbal N, Seshadri $\mathrm{P}$, et al. (2004) The effects of low-carbohydrate versus conventional weight loss diets in severely obese adults: one-year follow-up of a randomized trial. Ann Intern Med 140, 778-785.

24. Levey AS, Coresh J, Greene T, et al. (2006) Using standardized serum creatinine values in the modification of diet in renal disease study equation for estimating glomerular filtration rate. Ann Intern Med 145, 247-254.

25. Oxman AD, Schünemann HJ, Fretheim A, et al. (2006) Improving the use of research evidence in guideline development: 8. Synthesis and presentation of evidence. Health Res Policy Syst 4, 20.

26. Schünemann HJ, Fretheim A, Oxman AD, et al. (2006) Improving the use of research evidence in guideline development: 10. Integrating values and consumer involvement. Health Res Policy Syst 4, 22.

27. Moher D, Liberati A, Tetzlaff J, et al. (2009) Preferred reporting items for systematic reviews and meta-analyses: the PRISMA statement. PLoS Med 6, e1000097.

28. Tanaka M, Fukui M, Okada H, et al. (2014) Low serum bilirubin concentration is a predictor of chronic kidney disease. Atherosclerosis 234, 421-425.

29. Tirosh A, Golan R, Harman-Boehm I, et al. (2013) Renal function following three distinct weight loss dietary strategies during 2 years of a randomized controlled trial. Diabetes Care 36, 2225-2232.

30. Mantel N \& Haenszel W (1959) Statistical aspects of the analysis of data from retrospective studies of disease. $J$ Natl Cancer Inst 22, 719-748.

31. Higgins JP \& Thompson SG (2002) Quantifying heterogeneity in a meta-analysis. Stat Med 2, 1539-1558.

32. Brinkworth GD, Noakes M, Keogh JB, et al. (2004) Long-term effects of a high-protein, low-carbohydrate diet on weight control and cardiovascular risk markers in obese hyperinsulinemic subjects. Int J Obes Relat Metab Disord 28, 661-670.

33. Rolland C, Hession M, Murray S, et al. (2009) Randomized clinical trial of standard dietary treatment versus a lowcarbohydrate/high-protein diet or the LighterLife Programme in the management of obesity. J Diabetes 1, 207-217.

34. Brinkworth GD, Buckley JD, Noakes M, et al. (2010) Renal function following long-term weight loss in individuals with abdominal obesity on a very-low-carbohydrate diet vs highcarbohydrate diet. J Am Diet Assoc 110, 633-638.

35. Larsen RN, Mann NJ, Maclean E, et al. (2011) The effect of high-protein, low-carbohydrate diets in the treatment of type 2 diabetes: a 12 month randomised controlled trial. Diabetologia 54, 731-740.

36. Friedman AN, Ogden LG, Foster GD, et al. (2012) Comparative effects of low-carbohydrate high-protein versus low-fat diets on the kidney. Clin J Am Soc Nephrol 7, 1103-1111.

37. Yamada Y, Uchida J, Izumi $\mathrm{H}$, et al. (2014) A noncalorie-restricted low-carbohydrate diet is effective as an alternative therapy for patients with type 2 diabetes. Intern Med 53, 13-19.

38. Wal JS, McBurney MI, Moellering N, et al. (2007) Moderatecarbohydrate low-fat versus low-carbohydrate high-fat meal replacements for weight loss. Int J Food Sci Nutr 58, 321-329.

39. Goldstein T, Kark JD, Berry EM, et al. (2011) The effect of a low carbohydrate energy-unrestricted diet on weight loss in obese type 2 diabetes patients - a randomized controlled trial. Eur J Clin Nutr 6, e178-e186.

40. Wadden TA, Webb VL, Moran CH, et al. (2012) Lifestyle modification for obesity: new developments in diet, physical activity, and behavior therapy. Circulation 125, 1157-1170.

41. Foster GD, Wyatt HR, Hill JO, et al. (2010) Weight and metabolic outcomes after 2 years on a low-carbohydrate versus low-fat diet: a randomized trial. Ann Intern Med $\mathbf{1 5 3}$, $147-157$

42. Nordmann AJ, Nordmann A, Briel M, et al. (2006) Effects of low-carbohydrate vs low-fat diets on weight loss and cardiovascular risk factors: a meta-analysis of randomized controlled trials. Arch Intern Med 166, 285-293.

43. Naude CE, Schoonees A, Senekal M, et al. (2014) Low carbohydrate versus isoenergetic balanced diets for reducing weight and cardiovascular risk: a systematic review and metaanalysis. PLOS ONE 9, e100652.

44. Dansinger ML, Gleason JA, Griffith JL, et al. (2005) Comparison of the Atkins, Ornish, Weight Watchers, and Zone diets for weight loss and heart disease risk reduction: a randomized trial. JAMA 293, 43-53.

45. Cachat F, Combescure C, Cauderay M, et al. (2015) A systematic review of glomerular hyperfiltration assessment and definition in the medical literature. Clin J Am Soc Nephrol 10, 382-389.

46. Helal I, Fick-Brosnahan GM, Reed-Gitomer B, et al. (2012) Glomerular hyperfiltration: definitions, mechanisms and clinical implications. Nat Rev Nephrol 8, 293-300.

47. Yancy WS Jr, Olsen MK, Guyton JR, et al. (2004) A lowcarbohydrate, ketogenic diet versus a low-fat diet to treat obesity and hyperlipidemia: a randomized, controlled trial. Ann Intern Med 140, 769-777.

48. Tay J, Thompson CH, Luscombe-Marsh ND, et al. (2015) Long-term effects of a very low carbohydrate compared with a high carbohydrate diet on renal function in individuals with type 2 diabetes: a randomized trial. Medicine (Baltimore) $\mathbf{9 4}$, e2181. 